\title{
Light and electron microscopy of corneal melting syndrome (Mooren's ulcer)
}

\author{
ROBERT D. YOUNG ${ }^{1}$ AND PETER G. WATSON ${ }^{2}$ \\ From 'Strangeways Research Laboratory, Cambridge, and the ${ }^{2}$ Department of Ophthalmology, \\ Addenbrooke's Hospital, Cambridge
}

SUMmaRY Three patients with corneal melting syndrome of Mooren are described all of whom required lamellar grafting for perforation of the cornea. All these grafts subsequently failed. Tissue excised during grafting was studied by light and electron microscopy. In all cases the conjunctiva contained large numbers of lymphocytes and plasma cells. The limbal cornea showed 3 distinct zones: the deep stroma was intact but contained a prominent macrophage infiltrate; in the mid stroma marked hyperactivity of fibroblastic cells was associated with disorganisation of the corneal lamellae; the outer stroma was heavily vascularised and infiltrated by lymphocytes and plasma cells, with destruction of the collagen matrix. At the advancing, undermined edge of the corneal ulcer the deep stroma was undisturbed, but in the superficial layers accumulation of fibroblastic cells and destruction of collagen was observed. No other cell types were found. All the failed grafts contained fibroblasts which appeared highly active, surrounded by disorganised collagen fibrils. In these patients destruction of both host and graft corneal stroma apparently resulted from the activity of fibroblastic cells.

The progressive corneal destruction described by Mooren ${ }^{1}$ in 1867 , in which the peripheral stroma is destroyed circumferentially, then centrally, with a characteristic overhanging inner edge, appears to be a distinct clinical entity. Removal of the stroma proceeds eventually to affect the entire cornea, which suffers drastic reduction in thickness (Fig. 1). Simultaneously its function becomes seriously impaired. Mooren's ulcer has been considered to exist in 2 forms, one benign, responsive to therapy, and usually found in elderly people, the other a progressive, often bilateral ulcer showing poor response to treatment and tending to occur in younger people. ${ }^{2}$ Unfortunately many ulcers due to divergence of course or response to treatment cannot be accommodated in this convenient classification, which may generate a falsely simplified impression of a complex underlying pathology. This is underlined by the range of histopathological data obtained in several studies of this rare condition. ${ }^{3-6}$.

The aetiology and relationship of Mooren's ulcer to systemic diseases are also poorly understood, and it has been suggested recently that the more general

Correspondence to Dr R. D. Young. Strangeways Research Laboratory, Worts' Causeway, Cambridge CB1 4RN. term 'corneal melting syndrome' would be more appropriate until this painful and destructive disorder can be more accurately characterised. ${ }^{7}$

In the study described here light and electron microscopy were used to examine corneal and conjunctival tissue obtained from 3 patients with

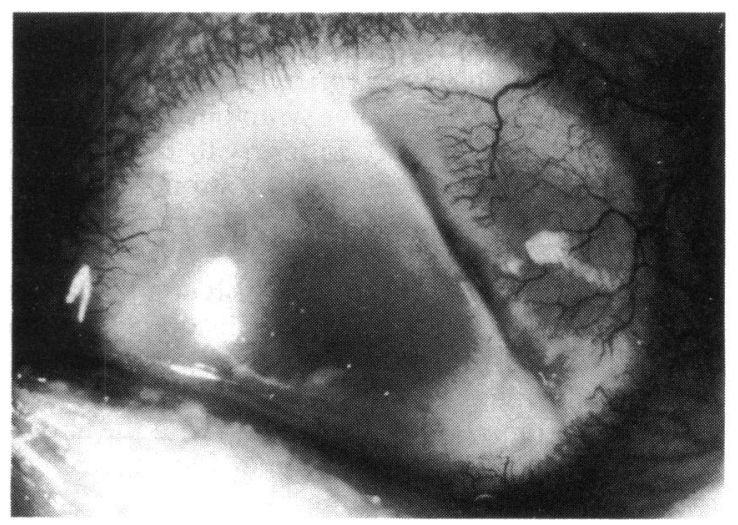

Fig. 1 Typical Mooren's ulcer showing vascularised, thinned peripheral cornea with undermined ulcerating edge. The remainder of the cornea appears only slightly 341 


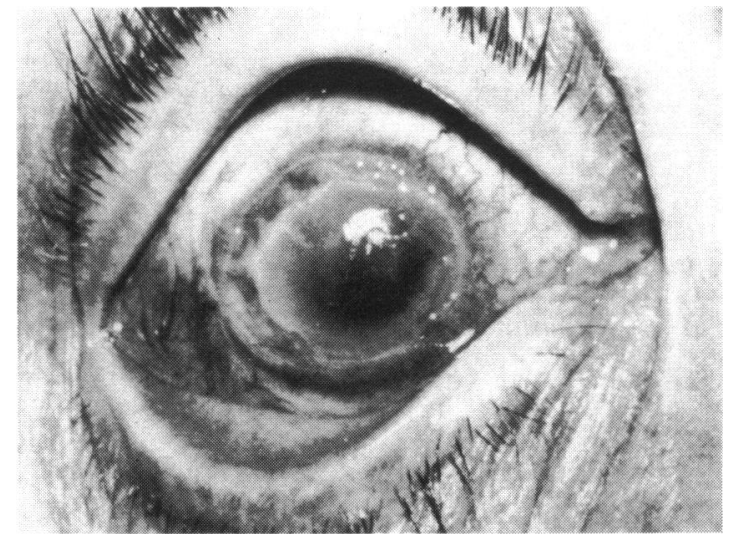

Fig. 2 Case 1 prior to first graft (1954) with almost complete, circumferential, peripheral corneal ulceration and deeply infiltrated, vascularised, and undermined corneal edge. The lower nasal quadrant of the cornea is relatively clear.

Mooren's disease who underwent grafting procedures. In one of these (case 3 ) further specimens were obtained when a second graft was performed after an interval of 10 months, thus providing an opportunity to assess the effect of grafting on the pathology of the disease. Possible mechanisms underlying the pathogenesis of Mooren's disease are discussed.

\section{Case histories}

\section{CASE 1}

This woman was first seen at the age of 43 with a history of transitory pain and redness in both eyes which settled spontaneously. One year later she suddenly developed a painful red left eye. Her vision became poor and the pain increased. She was treated for several months with a variety of drugs, including cortisone, which relieved her symptoms. The cornea showed a circumferential gutter, with oedema and diffuse infiltration of the central stroma. Some 6 months after onset the cornea became very thin $3 \mathrm{~mm}$ from the limbus and perforated.

Two days later the right eye, which up to this time had appeared completely normal, developed an episcleral congestion, localised between the 8 o'clock and $\mathbf{1 0}$ o'clock meridians, with a small deep corneal ulcer at the same site. The ulcer started at the limbus but was of maximum depth $3 \mathrm{~mm}$ from the limbal margin. General examination at this stage revealed nothing except a moderate hypertension (blood pressure $182 / 102 \mathrm{mmHg}$ ), an easily palpable, mobile right kidney, and advanced dental decay. She was admitted to hospital and treated with mydriatics, eye pad, and bandages, and although the perforation sealed itself the rest of the cornea began to ulcerate. Three weeks after admission there was a rapid deterioration in her vision, and the eye became very painful. It was found to be infected with Pseudomonas pyocyanea, which failed to respond to antibiotics. The left eye was therefore eviscerated 3 days later. At operation the whole globe was found to be infected and disorganised. Her teeth were extracted at the same time.

The peripheral corneal ulceration of the right eye extended in both directions around the limbus to affect the complete circumference within 3 months (Fig. 2). Because of increasing pain, episcleral congestion, and corneal ulceration, the entire cornea was covered with a Gunderson-type flap, which unfortunately retracted completely within 5 days.

Shortly afterwards the eye became more comfortable, but the cornea was oedematous and vascularised. Vision was reduced to counting fingers. In 1956, when the eye had been quiet for about one year, a $5 \mathrm{~mm}$ penetrating keratoplasty was performed. The whole thickness of the cornea was found to be oedematous, opaque, and to contain 'soft pultaceous material of questionable pathological activity.' The graft took well and remained clear during the postoperative period. She was continued on cortisone drops taken twice daily and given a course of ${ }^{32} \mathrm{P}$ B radiation therapy (400 rads), which successfully arrested the growth of fine blood vessels invading the graft in the upper nasal periphery. Graft clarity was preserved for over 12 months, when quite suddenly the epithelium became oedematous and sloughed.

On readmission for further grafting her cornea was generally cloudy, with numerous precipitates on the posterior surface. An annular lamellar keratoplasty was attempted but abandoned when the anterior chamber was penetrated. The cornea was covered with a conjunctival flap.

One month later a $9 \mathrm{~mm}$ lamellar keratoplasty was performed. This remained clear for about 6 months, when it was noted that the lower nasal quadrant had become 'gossamer thin' (Fig. 3). On 9 September 1960,7 years after the onset of the condition, a total corneal graft was performed together with an iridectomy, sphincterectomy, cirumferential cyclodialysis, extracapsular cataract extraction, and anterior chamber washout. This restored the vision to $6 / 60$ with correction. One month later the peripheral cornea again became thin and had to be resutured. It was again covered with a conjunctival flap. After this the cornea rapidly opacified, and a further fullthickness, total corneal replacement was undertaken 3 weeks later. This stayed clear for 1 week, restoring vision temporarily to $6 / 24$, before rapidly sloughing inwards from the periphery to affect the whole 


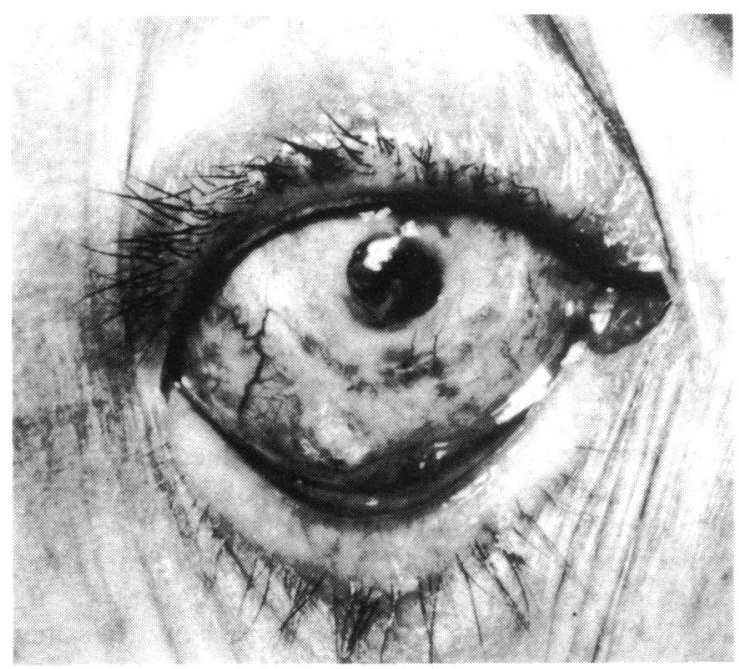

Fig. 3a

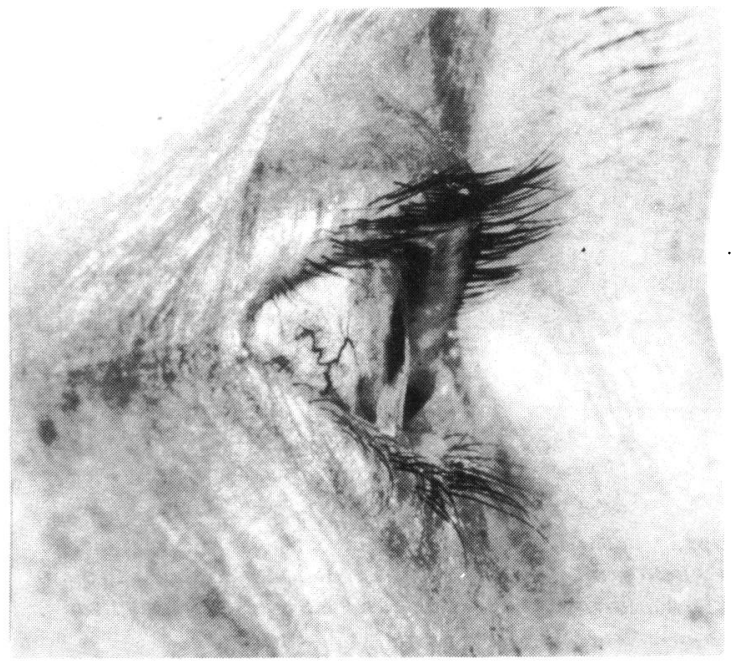

Fig. 3b

Fig. 3a, b Case 1 after first graft (1960) demonstrates clear central transparent descemetocele following destruction of $9 \mathrm{~mm}$ lamellar keratoplasty.

stroma. The small central island was removed in December 1960 and a total lamellar keratoplasty and conjunctival flap performed.

Although this conjunctival flap retracted, limited vision was possible through the thin atrophic scar for 8 years. Increased corneal scarring then made vision impossible (Fig. 4) and a further full-thickness, $7 \mathrm{~mm}$ keratoplasty was done with tissue-typed material. A good match was obtained. The graft remained clear for 3 days before oedema developed, and a deep gutter appeared on the host side of the graft interface. This gutter progressed over the next 3 days giving rise to 3 holes, one of which leaked. The graft was covered with conjunctiva, and, although it stopped the leakage and permitted clearing of the donor cornea, the entire periphery of the remaining host cornea became very thin.

Consequently a total anterior segment graft was performed in which remnants of the cornea, sclera, iris, and lens were removed and replaced with an intact corneoscleral segment from a size-matched donor. Excised tissues were processed for light microscopy. Within 24 hours the new anterior chamber contained aqueous and a small diffuse haemorrhage. Corneal clarity persisted but with marked folding in Descemet's membrane. The applanation pressure was $6 \mathrm{mmHg}$, with vision of counting fingers. Only a poor view could be obtained of the fundus because of the presence of an anterior vitreous membrane and thin, diffuse haemorrhages, but it appeared normal.

The eye remained quiet for 1 month, then 2 small areas of infiltrate appeared at the corneoscleral margin, which in less than one week extended over the whole limbal cornea. She had been given $30 \mathrm{mg}$ prednisolone from the time of the operation, and to this was added $300 \mathrm{mg}$ azothioprine, reducing to 150 $\mathrm{mg}$ per day. There was no further extension of the ulcer for one month, when the whole peripheral cornea became densely infiltrated, followed by the central corneal stroma over the next 6 months (Fig. 5). This corneal tissue was spontaneously removed, and a thin atrophic scar was left. No further surgery was attempted before the patient's death from pneumococcal pneumonia at the age of 66 in 1975.

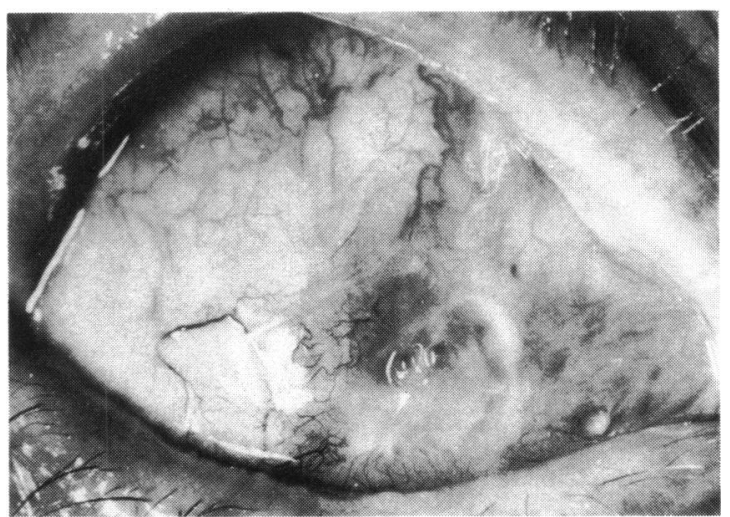

Fig. 4 Case 1 after fifth graft (1968). Fibrosis of the thin atrophic scar through which she had seen for 8 years. 


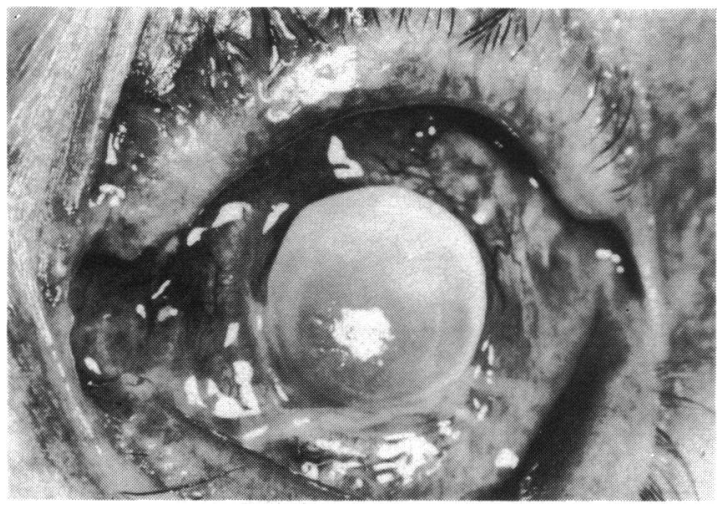

Fig. 5 Case 1 (1969). Appearance following total anterior segment graft showing ulceration of donor cornea with donor sclera uninvolved. Corneal destruction resembles typical Mooren's ulceration in ungrafted corneas.

\section{CASE 2}

In July 1973 this 58-year-old woman suddenly developed severe pain, associated with photophobia and watering, in her right eye. There was no history of injury or of other systemic disorders. Within one week the left eye became red but was not as painful as the right. Both corneas were oedematous when first seen, and there was a small guttered ulcer adjacent to the limbus of her right eye. Both eyes were treated with an intensive course of steroid eye drops which resolved the pain, corneal oedema, and inflammation, though both corneas remained scarred.

About 12 months later both eyes became extremely painful, and she presented with the same corneal appearance. This time, however, discomfort was not reduced by a course of local steroids. Vision gradually failed to hand movements in the left eye, and there was a progressive loss of tissue in the lower half of the left cornea (Fig. 6). The right eye became quiescent, and, although very thin, the corneal scar remained strong and inflammation slowly cleared (Fig. 7).

In July 1977 vision suddenly deteriorated in the left eye, and the thinned cornea perforated. She was admitted to hospital and a $9 \mathrm{~mm}$ lamellar keratoplasty was performed. All necrotic corneal tissue was removed to the level of Descemet's membrane and the donor cornea sutured into this bed. No attempt was otherwise made to seal the perforation. The graft cleared normally, although for a period 2 anterior chambers were detectable below the graft centre.

After 3 months this graft suddenly became oedematous, but there was no apparent destructive change in the cornea until June 1978, 10 months after grafting. Then the eye became red and painful, and a peripheral corneal gutter appeared in the donor tissue. She was readmitted to hospital, and a $6 \mathrm{~mm}$ penetrating keratoplasty was placed through the old graft. The cataractous lens was also removed in addition to some adhesions of the iris to the old perforation site. The excised corneal button was taken for microscopy.

After the graft the previous limbal inflammation and guttering resolved, and graft clarity persisted for one month. Then the first donor lamellar graft became swollen from 6 to 4 o'clock below, but the central corneal button remained entirely clear.

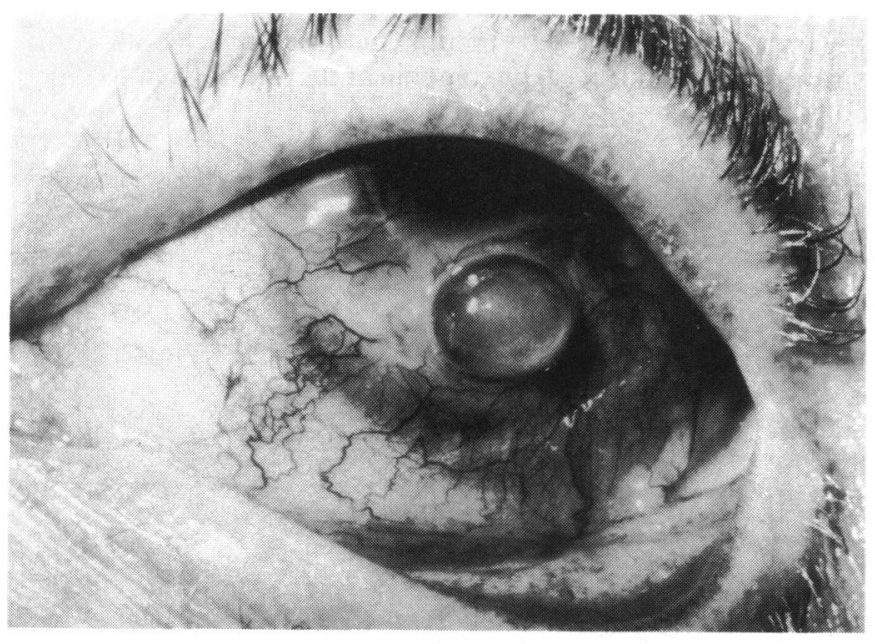

Fig. 6a

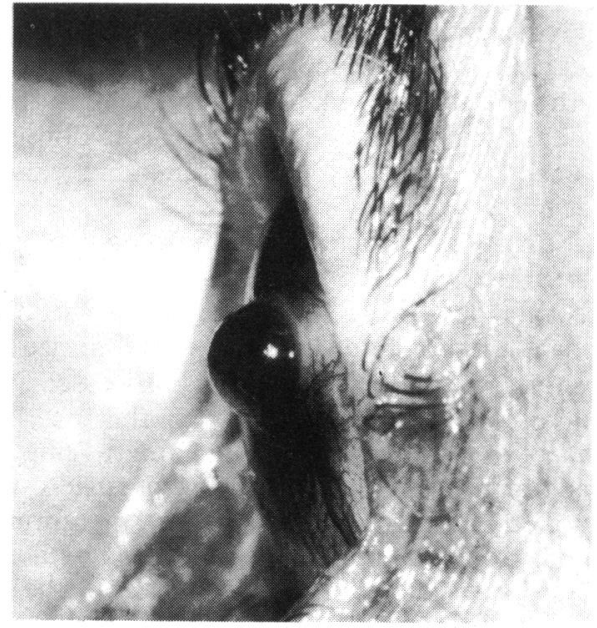

Fig. 6b

Fig. 6a, b Case 2 showing left eye at presentation. Descemetocele formation in previously ulcerating cornea. The cornea is transparent and undamaged superiorly. 


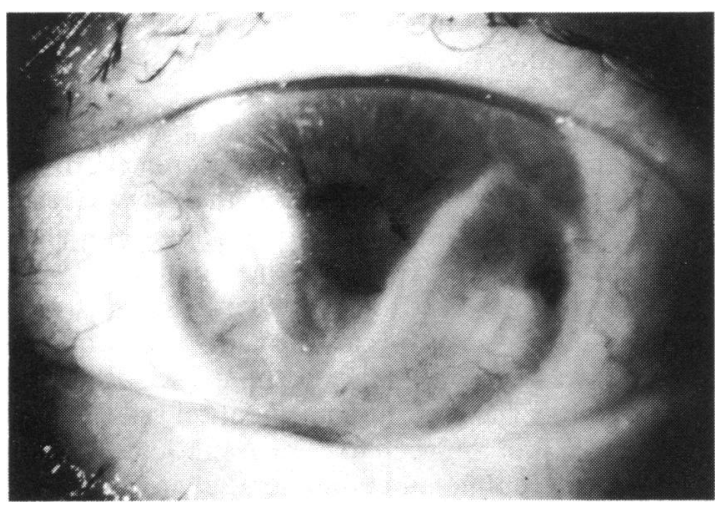

Fig. 7 Case 2 showing right eye at presentation. Quiescent, spontaneously healed, thinned peripheral cornea with anterior synechiae formation at 8 and $4 o^{\prime}$ clock.

However, one month later, in January 1979, a gutter advanced between 2 and 4 o'clock in the central penetrating graft. This rapidly extended centrally, but was successfully arrested by an intensive course of local and systemic steroids and the application of a soft contact lens. This restored her vision to $6 / 36$. The rest of the cornea remained clear for a further year, when it became opaque. However, there have been no more episodes of destructive corneal changes. The right eye has remained quiescent throughout this period.

CASE 3

In June 1973 this 57 -year-old woman injured her left eye while working at a threshing machine. This did not require any immediate treatment, but 5 days later she suddenly developed severe pain in this eye. She consulted her doctor, who treated her for 2 weeks with hydrocortisone drops. As there was no improvement in the eye, she was referred to hospital and was immediately admitted.

At this time the right eye was completely normal, with a vision of $6 / 6$. The left vision was reduced to $6 / 36$, and a deep undermined corneal ulcer was noted involving the whole of the nasal margin and extending to the 2 o'clock meridian on the temporal side. The conjunctiva was congested in the region of ulceration but not elsewhere. A complete tarsorrhaphy was undertaken in 2 stages in order to cover the cornea completely. In spite of this the pain persisted, and during the succeeding month the cornea swelled and became completely opaque. Over a period of 2 years the cornea vascularised, the eye became phthisical, and vision was lost.

Five years later, in June 1978, she had a sudden onset of pain in her right eye. She was readmitted to hospital where the vision was found to be $6 / 18$ in the

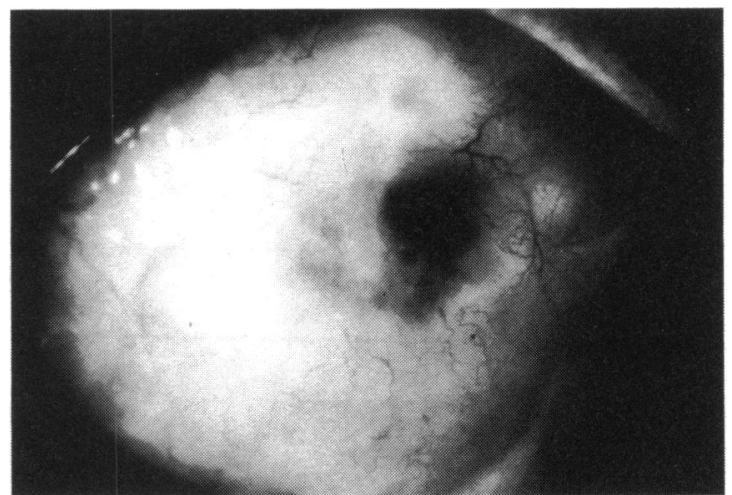

Fig. 8 Case 3 prior to first graft. The cornea is opaque and heavily vascularised with descemetocele formation at 2 o'clock.

right eye and no perception of light in the left eye. The right cornea was completely oedematous and only semi-transparent. In the 3 and 9 o'clock meridians there were deep, limbal corneal ulcers with associated stromal infiltration to the depth of Descemet's membrane. The infiltration continued to a lesser extent adjacent to the limbus throughout the whole circumference of the globe.

In July 1978 the limbal conjunctival tissue was excised. This resulted in healing of the corneal ulcers, a diminution of the corneal oedema, and some reduction in infiltration and injection of the eye. She was discharged, but within one week the pain had returned, and on readmission vision had fallen to $6 / 60$ and the ulcers were found to have recurred. On this occasion the left eye was removed and the right cornea was covered with a Gunderson flap, which adhered to the ulcerated areas to leave a central clear zone, giving reasonable vision of $6 / 36$.

The situation remained almost static for 12 months, when the ulcer recurred. The vision was found to be $2 / 60$, with the cornea opaque and vascularised. Vascularisation was largely superficial and most apparent in areas adjacent to the ulcers. A further conjunctival excision was performed, but there was no improvement in the vision or in the appearance of the eye.

When we first saw the patient in October 1980 the visual acuity was hand movements only in her right eye. The cornea was thin and heavily vascularised from 11 o'clock, around the entire lower half, to 2 o'clock on the nasal side. The upper wedge of cornea was free of vessels, although opaque, and there was a Descemetocele in the upper temporal quadrant (Fig. $8)$.

Investigation revealed a polyclonal increase in IgG to $15.5 \mathrm{~g} / \mathrm{l}$ (normal 7-13); however, conjunctival 


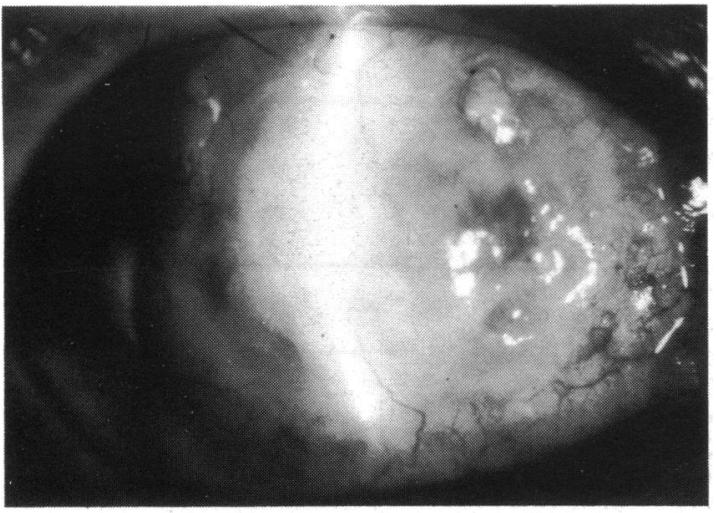

Fig. 9 Case 3 prior to second graft. Original 9 mm lamellar graft has been destroved leaving a very thin, opaque cornea.

biopsy revealed no positive immunofluorescence staining for IgG, but it did induce blast cell transformation when cultured with the patient's lymphocytes. All other investigations, including ultrasonography of the posterior segment, were normal.

In October 1980 a $9 \mathrm{~mm}$ lamellar keratoplasty was performed in which the stroma was removed to Descemet's membrane throughout the whole area. Excised tissue was used for immunological and histological studies. The site thus prepared was covered with a $0.5 \times 9 \mathrm{~mm}$ lamellar graft of fresh donor material from a 20-year-old man. Postoperative treatment was with antibiotic and prednisolone drops every 2 hours. The graft remained entirely clear for 3 weeks and vision returned to 6/36. At about this time the corneal epithelium and underlying stroma became slightly oedematous and thin, and then in early December, 8 weeks after the operation, a gutter developed in the graft between 4 and 8 o'clock. This rapidly extended, and within 2 weeks there was a crescentic defect involving a quarter of the graft. The advancing edge of the ulcer had a thickened, undermined edge. She was, however, able to see
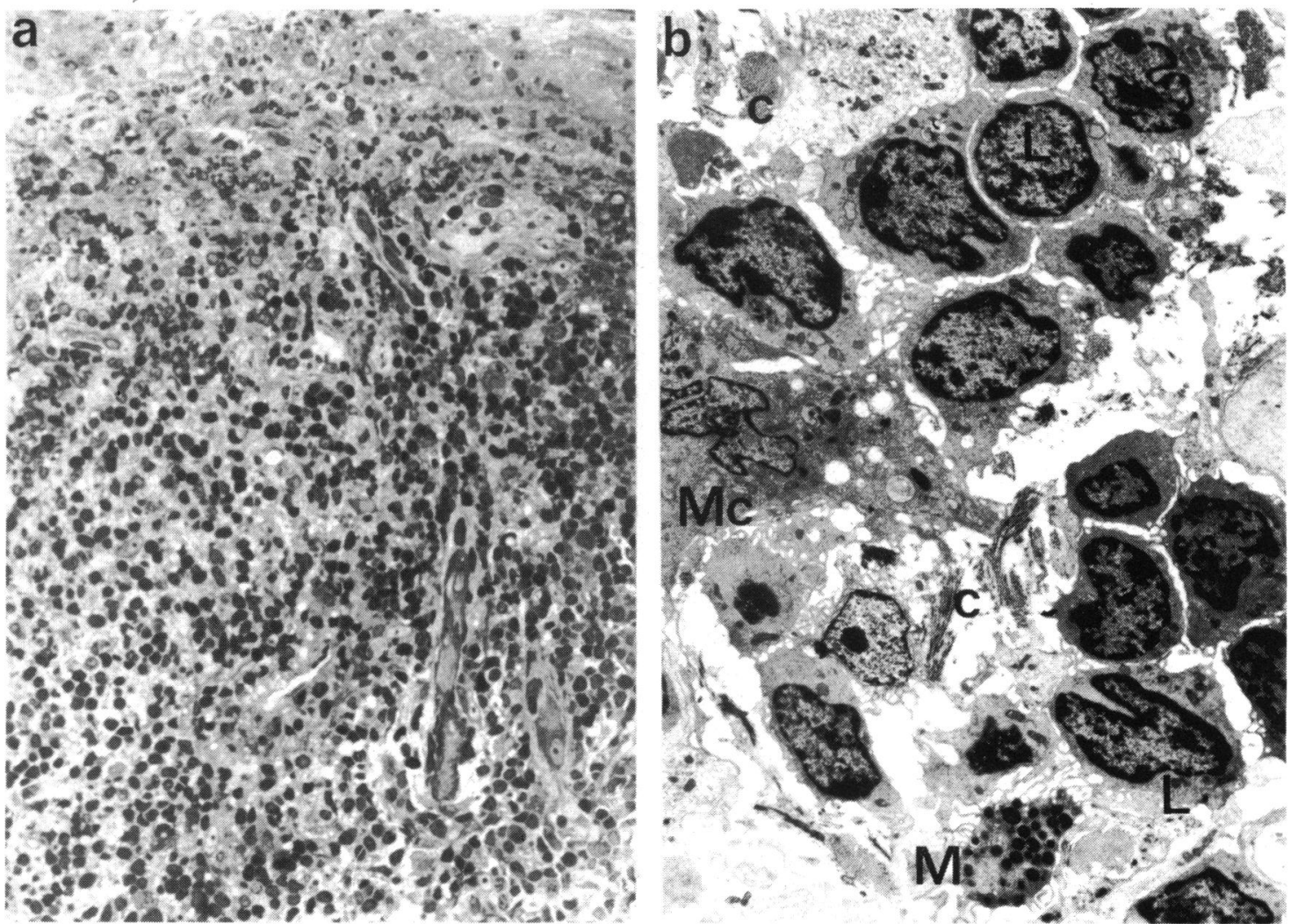

Fig. 10 Conjunctiva. a. Light micrograph showing intact conjunctival epithelium and cellular infiltration of underlying stroma $(\times 192)$. b. Electron micrograph illustrates dense clustering of stromal lymphocytes $(L)$, a mast cell $(M)$, macrophage $(\mathrm{Mc})$, and collagen fibrils $(\mathrm{c}) .(\times 3,400)$. 
adequately for 6 months, at which point she ran out of medication. As soon as this was discontinued, pain recurred and her vision deteriorated. Itching, redness, and discomfort persisted until she was restarted on medication some 3 months later. By this time the whole of the graft was removed except for a very thin deep lamella (Fig. 9). In August 1981 a further $11 \mathrm{~mm}$ lamellar keratoplasty and limbal conjunctival excision was performed in a similar manner to the original graft. The donor was a 59-year-old female. Excised tissue was again taken for microscopy.

Postoperatively she has been treated with prednisolone and azothioprine, and apart from a few epithelial bullae the graft has remained clear. Immunofluorescence staining for IgG in conjunctiva and cornea has again been negative.

\section{Methods}

In Case 1 the excised anterior segment was fixed in buffered formalin and embedded in paraffin wax. Sections were stained in haematoxylin and eosin.

Tissue excised from cases 2 and 3 was fixed for 2 hours at room temperature in $2.5 \%$ glutaraldehyde, buffered to $\mathrm{pH} 7 \cdot 2$ with $0 \cdot 1 \mathrm{M}$ sodium cacodylate containing $3 \mathrm{mM} \mathrm{CaCl}{ }_{2}$. After washing in buffer at $4^{\circ} \mathrm{C}$ it was postfixed in buffered $1 \%$ osmium tetroxide for 1.5 hours at room temperature, dehydrated in ethyl alcohol, cleared in propylene oxide, and embedded in Araldite.

Thick sections (approximately $1 \mu \mathrm{m}$ ) were stained in $1 \%$ toluidine blue in $1 \%$ aqueous borax solution and used for light microscopy and orientation for ultramicrotomy.

Thin sections (approximately $700 \mathrm{~nm}$ ) were stained in alcoholic uranyl acetate and lead citrate and examined in an AEI EM6B or Philips 201C electron microscope.

\section{Observations}

\section{CONJUNCTIVA}

Specimens removed from all 3 cases revealed a normal intact epithelium and basement membrane, overlying a slightly swollen hyperaemic stroma which contained dramatic numbers of small lymphocytes (Fig. 10). These cells formed dense clusters, filling the subepithelial palisades of Vogt and extending deeper into the stroma. Some showed signs of necrosis. Smaller numbers of stromal plasma cells and scattered mast cells, most undergoing degranulation, were also identified in addition to native conjunctival fibroblasts and macrophages.

LIMBAL CORNEA

The limbus adjacent to the ulcer was examined only

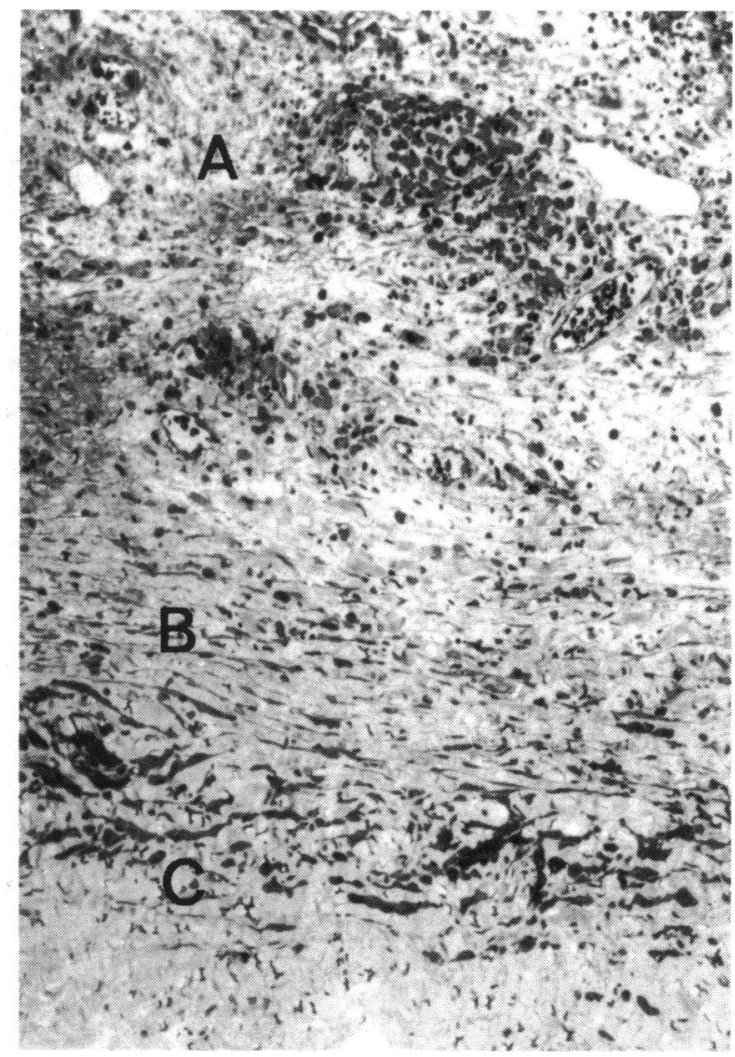

Fig. 11 Limbal cornea. A stratified organisation of the stroma is evident at this site comprising: A. a superficial stromal 'pannus' with perivascular accumulation of lymphocytes and plasma cells; B. an intact mid stromal zone containing attenuated fibroblastic cells; C. a deep stromal macrophage infiltrate. $(\times 145)$.

in case 3, where an apparent stratified organisation was discovered (Fig. 11). This comprised an outer, necrotic, heavily vascularised 'pannus,' infiltrated with lymphocytes and plasma cells, an underlying zone with many attenuated cells, and deep to this a narrow band of large, densely staining irregular cells.

Few viable fibroblasts could be located in the outer ulcerated stroma. In contrast, plasma cells and small lymphocytes were relatively numerous (Fig. 12), especially in the vicinity of superficial blood capillaries. Extravascular red blood corpuscles were a common feature at this level. Mast cells were less frequently observed than in conjunctival tissue. The collagenous component of the distal stromal matrix exhibited an advanced state of destruction, with large tracts of necrotic stroma occupied by pycnotic cells and accumulations of extracellular organelles and membraneous structures. Various types of cytoplasmic granules were present free in the matrix, 


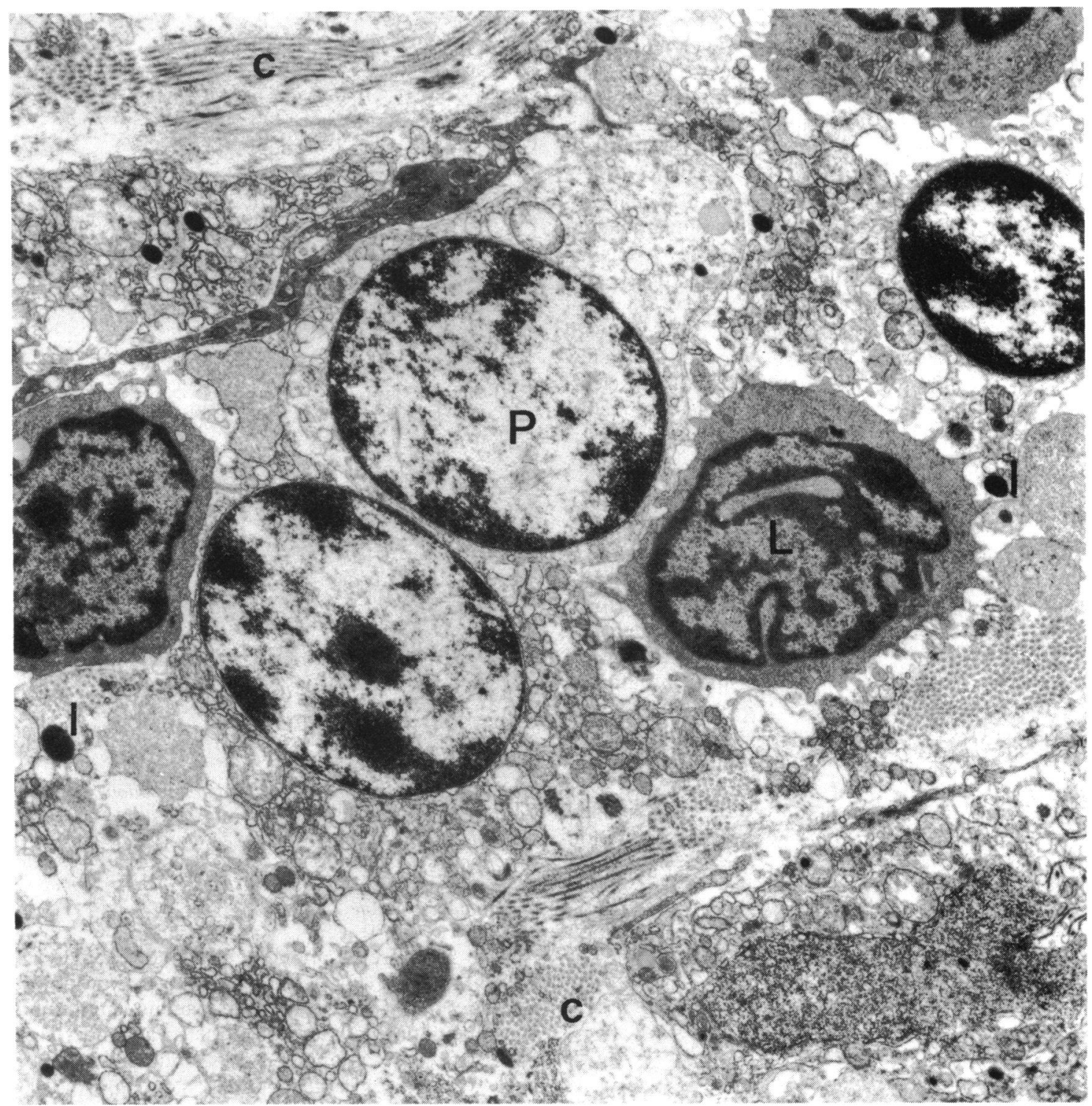

Fig. 12 Limbal cornea. Electron micrograph of superficial stroma showing lymphocytes $(L)$ and degeneration of plasma cells $(P)$. Cellular debris, including organelles and lysosomal granules (1) is abundant, but relatively few intact collagen fibrils (c) are present. $(\times 7800)$.

including lysosomal and mast cell granules (Figs. 12 and 13). The abundance of extracellular roughsurfaced endoplasmic reticulum (RER) and plasma cells in various stages of necrosis suggested that these cells made a major contribution to the high level of cell debris present (Fig. 12). Intact collagen fibrils were rarely seen in the superficial stroma, where they had largely been replaced with a diffuse amorphous or fine fibrillar substance (Fig. 13). Relatively few polymorphonuclear (PMN) leucocytes were located. These cells showed little evidence of phagocytosis of the abundant extracellular material available (Fig. 13). Observations of vascular tissue at the limbus suggested a high level of reorganisation, with smallvessel occlusion, destruction, and formation ensuing simultaneously (Fig. 14). New vessels were identified 


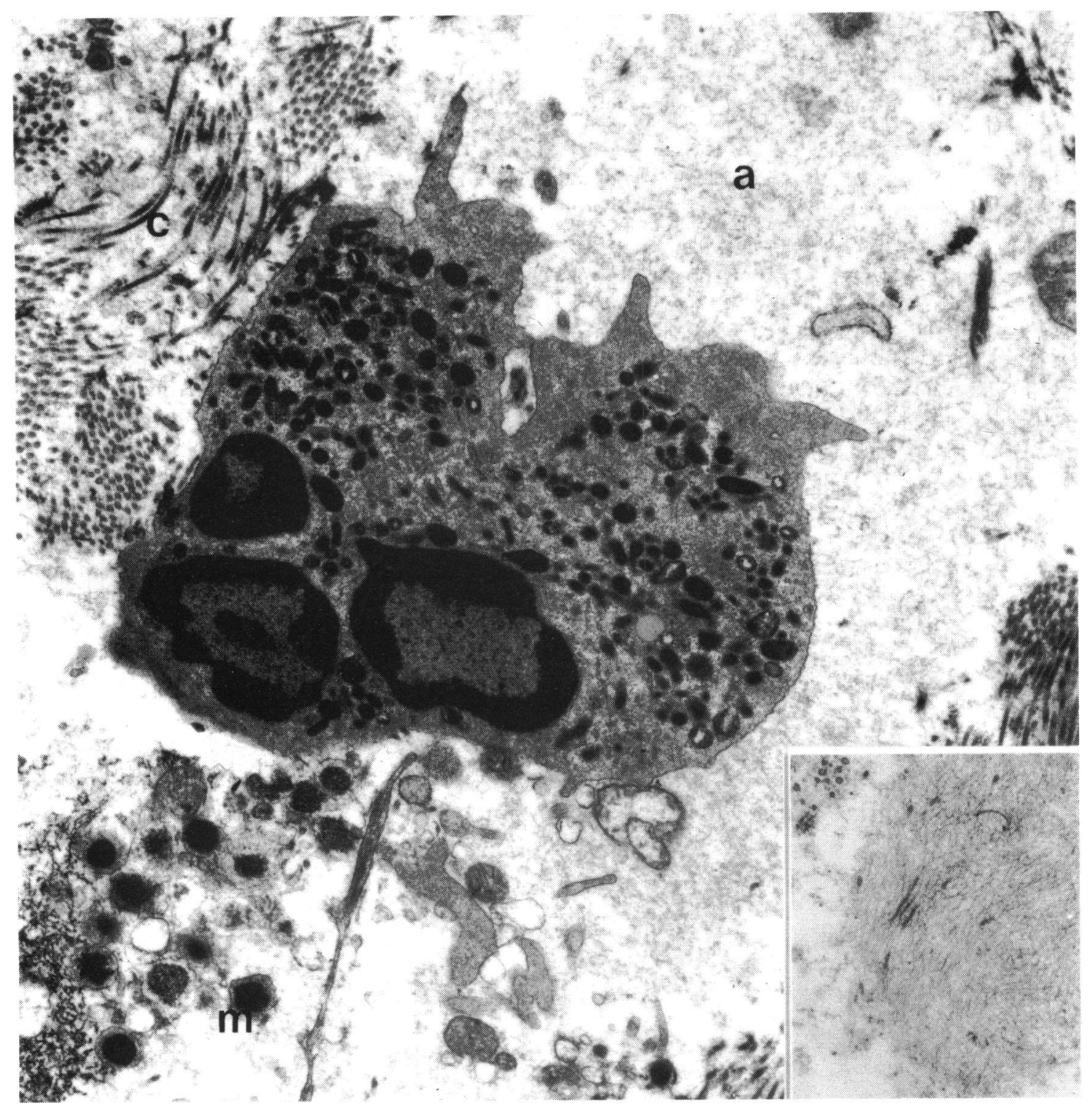

Fig. 13 Limbal cornea. A PMN leucocyte in superficial stroma shows little evidence of phagocytosis. The surrounding matrix contains extracellular mast cell granules $(m)$ and some intact collagen fibrils $(c) .(\times 11700)$. Elsewhere a diffuse amorphous substance $(a)$, or a fine fibrillar material (inset $\times 18200)$ is present.

as those of small diameter with bulky endothelial cells, surrounded by masses of basal lamina material and large attendant pericytes. Such vessels were commonly located at sites distal to the ulcer, while more centrally, towards actively ulcerating cornea, small vessels were frequently found with necrotic endothelium or completely ruptured walls (Fig. 14b).
Deeper in the limbal stroma (Fig. 11B) inflammatory leucocytes were scarce and the connective tissue matrix showed less advanced destructive changes. Here numerous fibroblasts containing prominent Golgi regions, mitochondria, and RER were present (Fig. 15). These cells were densely packed and displayed an increased cytoplasm:nucleus ratio over normal, corneolimbal 
fibroblasts. An impression gained from thick sections of an unaltered lamellar organisation in the mid stroma was not confirmed at higher magnification, whereupon it appeared markedly oedematous. Disorganisation of collagen fibrils and wide variation in interfibrillar distance were characteristic. In addition electron-dense cross-banded material and sprays of microfibrils, formed by the dissociation of individual collagen fibrils, were commonplace. Occasionally sections through stromal fibroblasts revealed collagen fibrils apparently contained within cytoplasmic vacuoles (Fig. 15b, c).

A band of large, irregular cells situated deep in excised limbal tissue was shown by electron microscopy to consist primarily of macrophages (Figs. 11C and 16). These contained extensive Golgi complexes and numerous elongate mitochondria. Intracytoplasmic granules were also numerous. Peripherally the macrophage cell membranes were often thrown into an elaborate veil of slender pseudopodia which surrounded individual cells and projected into the matrix (Fig. 16). Fibroblasts and lymphocytes were sometimes seen in close contact with macrophage veils. Disruption of stromal lamellae at this level resembled that described previously, except that here individual collagen fibrils retained their structural integrity.

\section{CORNEAL ULCER}

All 3 cases illustrated a typical thickening of epithelium immediately adjacent to the ulcer on its central edge (Fig. 17a). The corneal stroma which was denuded of epithelium overlying the ulcer was elsewhere surfaced with epithelial cells of normal thickness and structure. Bowman's layer was broken and distorted (case 3) or absent (cases 1 and 2) from the nonepithelialised portion of the ulcer and appeared sunken into subjacent necrotic stroma (Fig. 17b). There was no major accumulation of infiltrating leucocytes associated with the ulcerating corneal stroma. In case 1 polymorphonuclear leucocytes were scattered diffusely throughout the corneal stroma, both around the ulcer and in nonulcerating tissue. In contrast, hypercellularity of the superficial stroma in cases 2 and 3 resulted from a concentration of fibroblastic cells and the reduction in thickness of lamellae
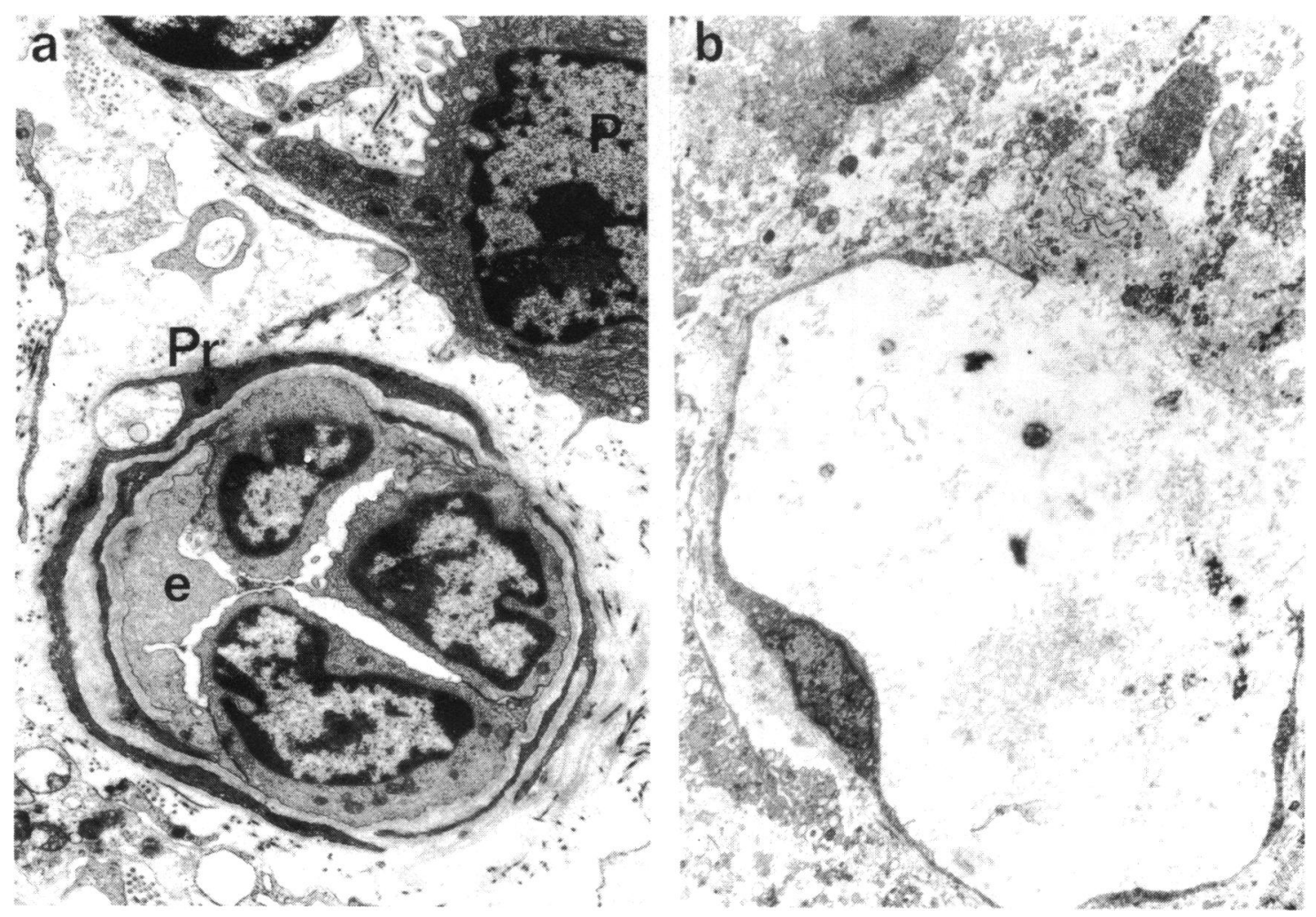

Fig. 14 Limbal cornea. a. Occlusion of a small capillary in superficial stroma; endothelial cells (e), pericytes (Pr) and plasma cell $(P) .(\times 3800)$. b. Capillary destruction in superficial stroma adjacent to corneal ulcer. $(\times 13500)$. 


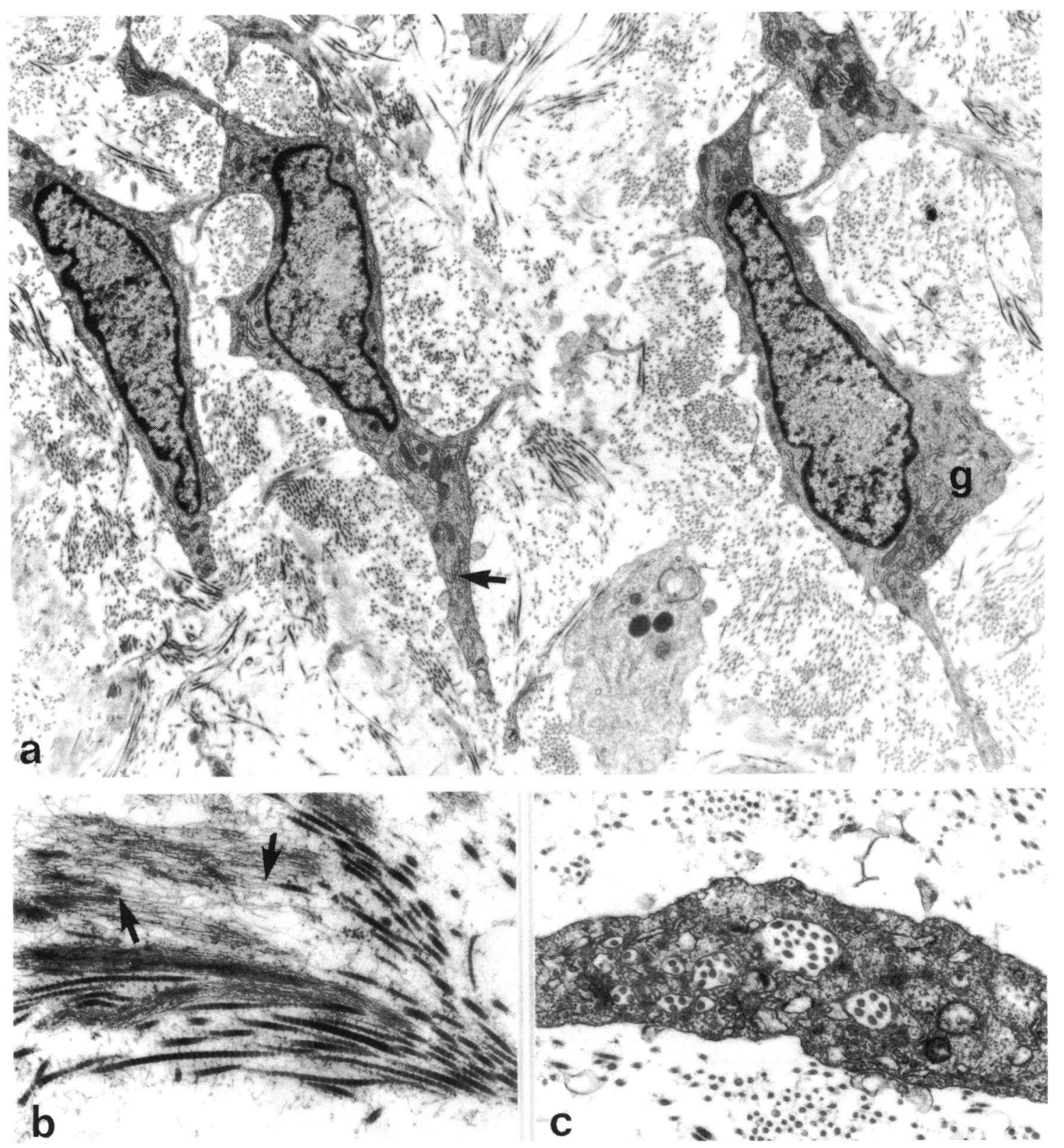

Fig. 15 Limbal cornea. a. Electron micrograph of mid stroma showing disorganisation of lamellae and presence of 'active' fibroblasts with prominent Golgi $(g)$, RER (arrow) and mitochondria. $(\times 6600)$. b. Mid stromal collagen fibrils appear dispersed into component microfibrils (arrows) $(\times 45000)$ or $\mathrm{c}$. contained within intracellular vacuoles. $(\times 30000)$.

(Fig. 17c). These cells showed varying stages of necrosis, including nuclear karyorrhexis and the development of autophagic vacuoles. Necrotic cells filled the upper stroma at the ulcer centre and peripherally around the fractured Bowman's layer in case 3. Specimens removed from cases 2 and 3 at regrafting showed cells of identical structure and organisation, lending a similar level of hypercellularity to the host corneal tissue where it apposed the margins of the graft. Although dissociation and apparent phagocytosis of stromal collagen fibrils, as recorded at the limbus, were present here also, the 

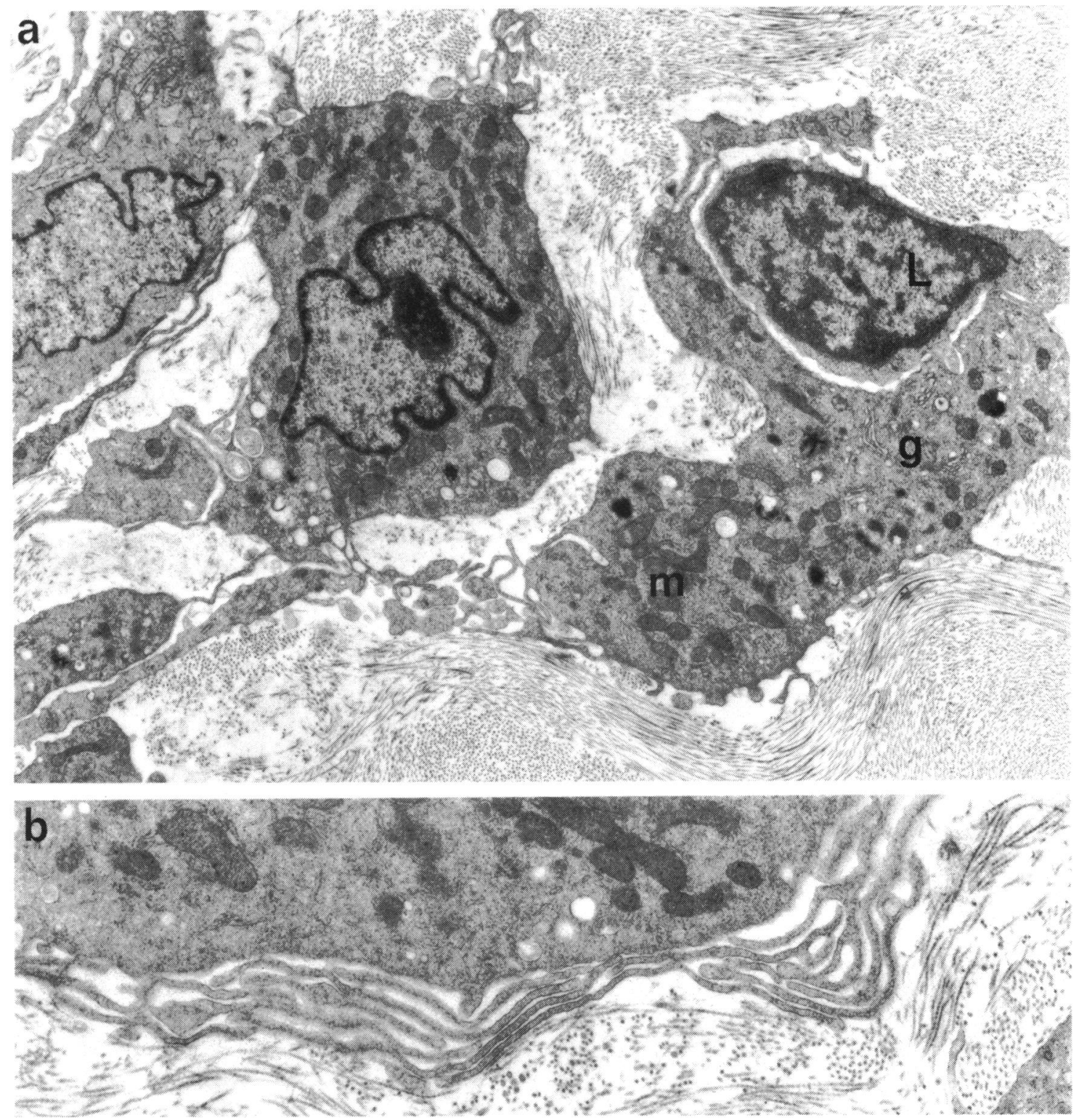

Fig. 16 Limbal cornea. a. A macrophage in the deep stroma, in close contact with a small lymphocyte $(L)$, contains an extensive Golgi complex $(\mathrm{g})$ and numerous mitochondria $(\mathrm{m}) .(\times 7500)$. b. Veil-like extensions of a macrophage cell membrane. $(\times 13500)$.

architecture of the deep stroma was relatively undisturbed.

\section{GRAFT STRUCTURE}

Observations of tissue from failed lamellar grafts were made in cases 2 and 3 at 13 and 10 months respectively following implantation. In general, preservation of epithelium, basement membrane, and Bowman's layer at the graft centre was excellent, but with an irregular surface contour in case 3 . In both cases graft stroma showed some heterogeneity, with zones of localised oedema causing both loss of lamellar organisation and disorganisation of collagen fibrils. In addition graft fibroblasts displayed several 

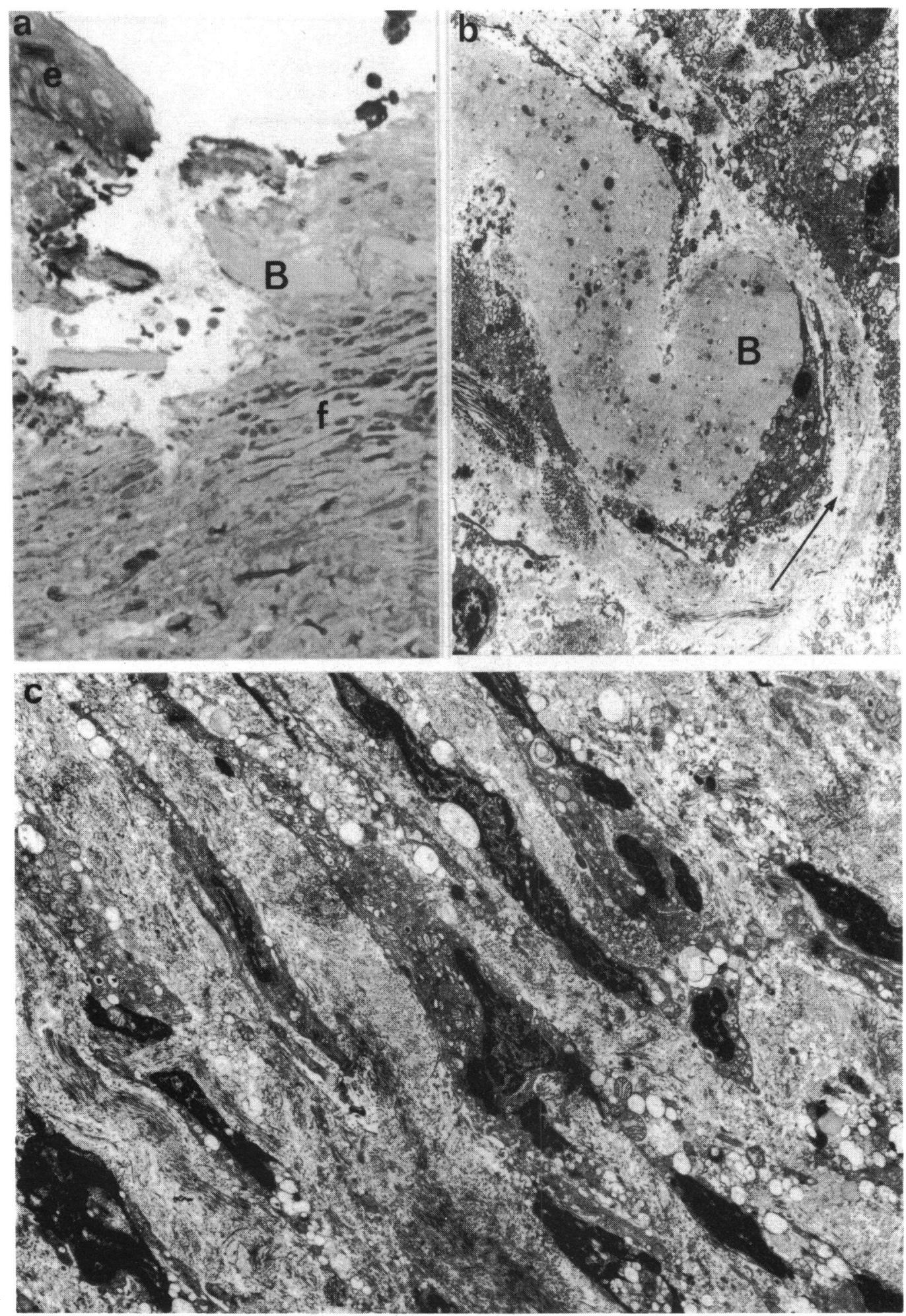

Fig. 17 Corneal ulcer. a. Light micrograph of corneal ulcer in case 3 showing thickened epithelium (e), fractured Bowman's laver $(B)$, and concentration of fibroblastic cells in superficial stroma $(f) .(\times 374)$. b. Fractured Bowman's layer $(B)$ is distorted and sunken into the underlying ulcerating stroma. Arrow indicates direction of corneal surface. $(\times 8000)$. c. Electron micrograph showing concentration of necrotic fibroblastic cells and reduction in superficial lamellae at ulcer site. $(\times 5200)$. 

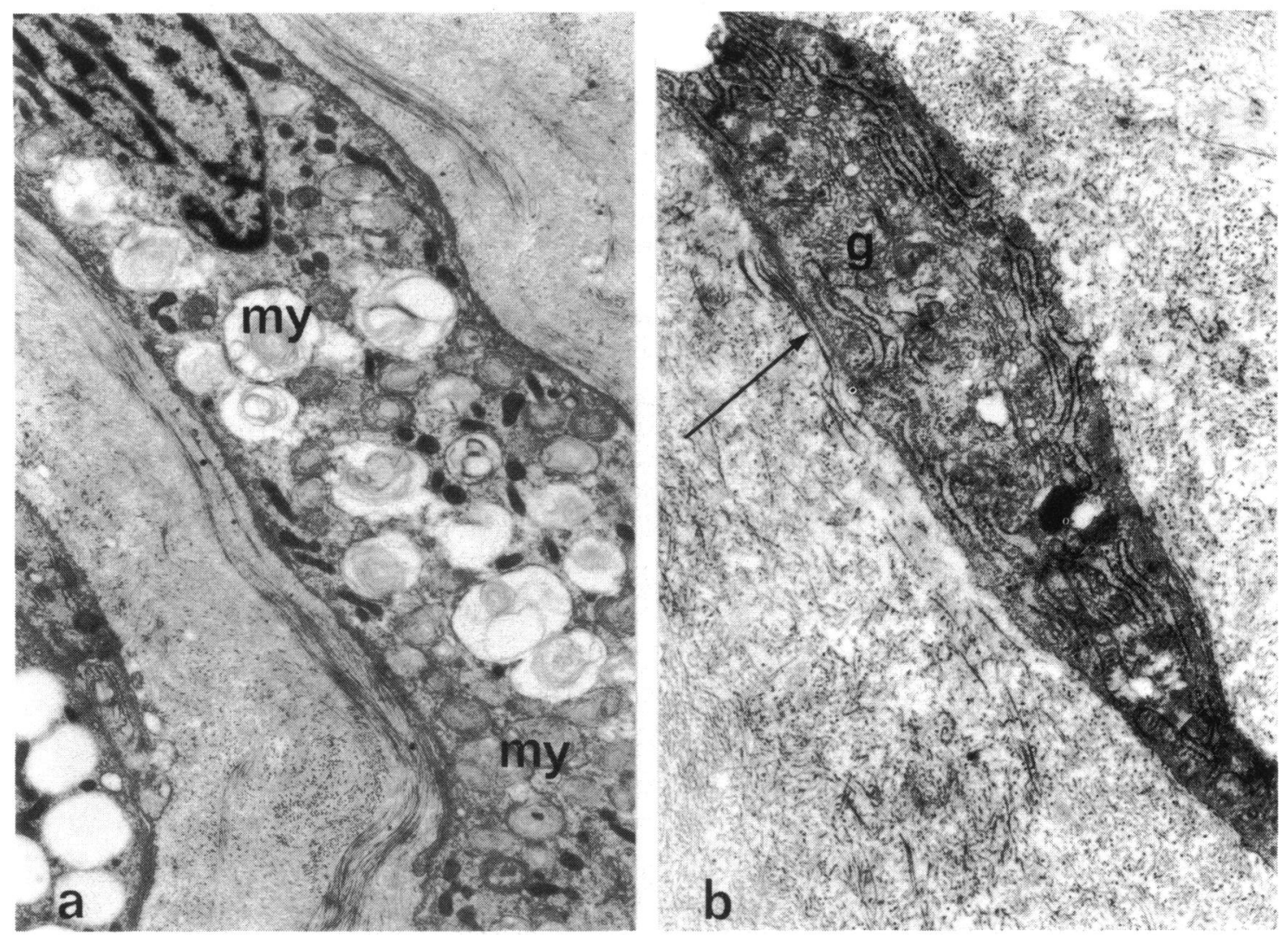

Fig. 18 Failed graft stroma. a. Vacuolation of cytoplasm and development of multiple myelin figures (my) in stromal cells of 10 months old lamellar graft. $(\times 7500)$. b. In the same graft a fibroblastic cell with prominent cytoplasmic organelles is located within a pocket of short disorganised collagen fibrils. Some fibrils (arrow) are aligned along the cell membrane, close to the Golgi complex (g). $(\times 11900)$.

changes. These cells appeared to be universally more active in terms of cell size, distribution of nuclear chromatin, and prominence of cytoplasmic organelles in comparison with stromal cells in normal unoperated corneas. Some showed signs of necrosis with grossly distorted nuclei, disintegration of organelles, and rupture of the plasma membrane. In case 3 many stromal cells appeared rounded and contained myelin figures and cytoplasmic vacuoles with extracted contents (Fig. 18a). In both cases 2 and 3 active cells were often located within distinct pericellular zones of short, randomly orientated collagen fibrils; these fibrils were sometimes closely apposed to the cell membrane and adjacent to the secretory organelles (Fig. 18b).

\section{Discussion}

The corneal melting syndrome of Mooren is clinically quite distinct from other forms of peripheral corneal ulceration such as those associated with systemic vasculitis, rheumatoid arthritis, polyarteritis nodosa, and Wegener's granulomatosis. It is essentially a painful, bilateral condition which is not associated with any systemic disease and which involves progressive peripheral, then central, destruction of the corneal stroma. Mooren's and other forms of peripheral corneal disease both begin with limbal inflammation and ulceration. An important difference, however, is that except in extreme cases of peripheral ulceration only Mooren's ulcers progress centrally and, unlike these other forms of ulceration, never invade adjacent scleral tissue. A characteristic feature of this disorder, seen in all cases reported here, is that, while the corneal periphery is opaque, deeply ulcerated, and extensively vascularised, unaffected tissues beyond the ulcerating front appear transparent and only slightly oedematous. When all the stromal tissue has been destroyed, the pain and inflammatory signs dis- 
appear. The cornea is replaced by a thin atrophic scar which is sometimes so thin that limited vision may be possible through it. Perforation of the cornea due to Mooren's ulcer, as in the 3 patients described here, is very unusual and is considerably less common than perforation due to other forms of corneal disease. Furthermore, corneal grafts are well tolerated in these latter cases provided the systemic condition is under control, whereas the prognosis for corneal grafts in patients with Mooren's disease is notoriously poor. Although the clinical presentation and course of these 3 patients were typical of the corneal melting syndrome of Mooren, each showed some unique feature.

In all 3 patients the onset was acute, with severe debilitating pain in the affected eye. One patient had some mild premonitory symptoms one year before and another had sustained an injury 5 days previously. All cases were bilateral. The second eye was affected 5 days after the first in case 1,6 months later in case 2 (at a stage when the first eye was very active), and 5 years later in case 3 following the loss of the first eye. Inflammation of the affected eye was in all cases confined to the limbus, and in no instance was the sclera involved.

On the precept that the limbal conjunctiva adjacent to the ulcer might be contributing to the corneal destruction, excision of limbal conjunctiva was performed in one patient. This effected a transitory improvement only. Conjunctival hooding was also undertaken, and although this produced some temporary relief of pain, the progression of the disease was unaltered.

Corneal grafts are not normally undertaken in the treatment of this condition because of the high frequency of graft failure in these patients and because corneal perforation is relatively uncommon. In all 3 patients described here the corneas perforated, making grafting essential. Unfortunately, none of the grafts, except one performed 18 months ago, has been successful. The nature of graft failure is also of some interest. For the first few postoperative days the grafted cornea remained clear and of normal thickness, after which it rapidly thickened and developed fine epithelial bullae. Grafts may be maintained in this condition either permanently or for many months provided limbal inflammation is prevented by continued use of local steroids. More often, however, a gutter develops at the periphery of the newly transplanted tissue. In one instance this was at the margin of a smaller graft inserted within an earlier, failed graft. In another it appeared at the margin of an $8 \mathrm{~mm}$ graft, adjacent to original host tissue. It is of considerable interest that, in the anterior segment graft which was performed, ulceration recommenced at the periphery of the donor cornea, but at no time was the donor sclera or the junction between host and donor sclera affected. The interval between successive rejection episodes was shorter with increased numbers of grafts, but good tissue matching gave no obvious improvement in retention of the graft. Steroid therapy either in large systemic or local doses had some effect in reducing inflammation, but most grafts still opacified or became thin, scarred, and semitransparent.

Although the clinical appearance of typical Mooren's ulcer is well known, in contrast attempts to describe the histopathological features of this disorder have not found universal agreement. In particular, considerable variation has been reported concerning the extent of inflammation associated with the ulcer. This ranges from the presence of few inflammatory cells, but an increased number of stromal keratocytes, ${ }^{4}$ to ulcers containing lymphocytes and polymorphonuclear (PMN) leucocytes, ${ }^{5}$ and to a case where PMN leucocytes were virtually the only type of infiltrating cell in cornea and conjunctiva. ${ }^{6}$ Except in case 1 , where bacterial infection was detected in the early course of the ulcer, the low incidence of PMN leucocytes was a conspicuous feature of all excised tissue in our patients. This is remarkable, particularly in relation to the absence of epithelium and Bowman's layer at the ulcer foci, in view of experimental studies where disruption of the corneal surface actually appeared to stimulate invasion of the stroma by PMN leucocytes. ${ }^{8}$ The nature and timing of the stimulus for such infiltration are, however, little understood. PMN leucocytes are known to contain abundant lysosomal hydrolase enzymes, including collagenase, 910 and have been highly implicated as agents of corneal matrix destruction in one ultrastructural study of Mooren's disease. ${ }^{6}$ However, in our ultrastructural studies of the region of active ulceration in 3 cases corneal matrix destruction was located in the presence of fibroblast-like cells, possibly activated cells of the corneal stroma.

The presence of large numbers of lymphocytes and plasma cells as seen in the conjunctival stroma of our 3 cases was also reported in ulcers described previously. ${ }^{51112}$ This observation would seem to substantiate the view of conjunctival function as that of a local lymph node. ${ }^{13}$ In addition several authors using immunofluorescence techniques have shown positive staining for immunoglobulins in the conjunctival epithelium and stroma during this disease. $^{61114}$ No positive staining for IgG was observed in a conjunctival biopsy from case 3 , studied by this method. However, the presence of cell mediated immunity to conjunctival and corneal tissue was suggested by a positive result in an in-vitro lymphocyte stimulation assay. Other workers have 
also demonstrated cell mediated immunity in Mooren's disease using this method. ${ }^{611} 15$

The conjunctiva has been implicated as a possible source of proteolytic enzymes presumed responsible for corneal destruction. ${ }^{5}$ Brown showed lysis of collagen gels cultured in the presence of conjunctival stroma from patients with Mooren's disease. In addition, a high percentage, though not all, of ulcers treated by conjunctival excision showed improved healing, possibly due to the removal of the sites of enzyme production. ${ }^{216}$ However, the role of the conjunctiva as a source of proteolytic enzymes involved in corneal ulceration is questionable for several reasons: firstly, this study and others ${ }^{51112}$ have failed to demonstrate concentrations of conjunctival granulocytes or, on morphological criteria, other active cells which might represent the secretory machinery for such enzyme production; secondly, were sufficient enzymes released to mediate destruction of adjacent corneal tissue, one might reasonably expect the conjunctival stroma to show similar destructive changes, but this is not the case.

No previous ultrastructural studies of the limbal cornea in Mooren's disease have been reported. In one case where this was possible here, an interesting stratified organisation was evident. The salient feature of this region was an increase in the extent of stromal matrix destruction from the deeper layers outwards. This ranged from essentially intact deep stroma, infiltrated with macrophages, through the increasingly disorganised mid stroma containing active fibroblasts, to the outer layers where extensive degradation of stromal collagen fibrils and necrosis of fibroblasts was present. The damaged outer stroma contained conspicuous perivascular accumulations of lymphocytes and plasma cells.

The 3 corneal ulcers examined all illustrated the typical topography of Mooren's disease, with deepithelialised active zones and undermined central edges, where the overlying epithelium was much thickened. It should be emphasised that no concentrations of infiltrating cells were located at the ulcer foci. Instead, destruction of the superficial stroma was taking place in the presence of fibroblastic cells, while the deeper lamellae remained undisturbed. This situation prevailed both in the original ulcer and where peripheral ulceration recurred following grafting. It is also significant that failed grafts were similarly characterised by the absence of inflammatory leucocytes and by stromal cells, which appeared highly active in terms of their gross morphology and well developed organelles. These graft fibroblasts were apparently engaged in remodelling their surrounding matrix. We conclude therefore that, in these 3 patients with corneal melting syndrome of Mooren, destruction of both host and graft corneal stroma seemed to be dependent on the activity of fibroblastic cells. However, the modulation of corneal fibroblast activity by inflammatory cells at the limbus must be considered. This is vitally important in view of evidence from recent in-vitro experiments which suggests that diffusible factors, released by a variety of cell types in culture, including lymphocytes and macrophages, are able to enhance the capacity of connective tissue cells to degrade their matrix. ${ }^{17}{ }^{18}$ If similar mechanisms are involved in the pathogenesis of Mooren's disease, they may be directed specifically at cells in the corneal stroma, because adjacent scleral tissue, whether of host or donor origin, remains unscathed.

The authors gratefully acknowledge the support by a grant from the Wellcome Trust.

\section{References}

1 Mooren A. Ophthalmiatrische Beobachtungen. Berlin: Hirschwald, 1867.

2 Wood TO, Kaufman HE. Mooren's ulcer. Am J Ophthalmol 1971; 71: 417-22.

3 Feingold M. Mooren's ulcer of the cornea. Am J Ophthalmol 1921;4: 161-70.

4 Edwards WC, Reed RE. Mooren's ulcer. A pathologic case report. Arch Ophthalmol 1968; 80: 361-4.

5 Brown SI. Mooren's ulcer. Histopathology and proteolytic enzymes of adjacent conjunctiva. Br J Ophthalmol 1975; 59: 670-4.

6 Foster CS, Kenyon K. Greiner J, Greineder D, Friedland B, Allansmith M. The immunopathology of Mooren's ulcer. Am J Pathol 1979; 88: 149-59.

7 Brown SI. What is Mooren's ulcer? Trans Ophthalmol Soc UK 1978; 98: 390-2.

8 Kenyon KR, Berman M, Rose J, Gage J. Prevention of stromal ulceration in the alkali-burned rabbit cornea by glued-on contact lens. Evidence for the role of polymorphonuclear leukocytes in collagen degradation. Invest Ophthalmol Visual Sci 1979; 18: 570-87.

9 Bretz U, Baggiolini M. Biochemical and morphological characterisation of azurophil and specific granules of human neutrophilic polymorphonuclear leucocytes. J Cell Biol 1974; 63: 251-69.

10 Murphy G, Reynolds JJ, Bretz U, Baggiolini M. Collagenase is a component of the specific granules of human neutrophil leucocytes. Biochem J 1977; 162: 195-7.

11 Mondino BJ, Brown SI, Rabin BS. Cellular immunity in Mooren's ulcer. Am J Ophthalmol 1978; 85: 788-91.

12 Eiferman R, Hynduik R, Hensley G. Limbal immunopathology of Mooren's ulcer. Ann Ophthalmol 1978; 10: 1203-6.

13 Rahi AHS, Garner A. Immunopathology of the Eye. Oxford: Blackwell, 1976.

14 Brown SI, Mondino BJ, Rabin BS. Autoimmune phenomenon in Mooren's ulcer. Am J Ophthalmol 1976; 82: 835-40.

15 Easty DL, Madden P, Jayson MJ, Carter C, Noble BA. Systemic immunosuppression in marginal keratolysis. Trans Ophthalmol Soc UK 1978; 98: 410-7.

16 Brown SI. Mooren's ulcer. Treatment by conjunctival excision. Br J Ophthalmol 1975; 59: 675-82.

17 Saklatvala J, Sarsfield SJ. Lymphocytes induce resorption of cartilage by producing catabolin. Biochem $J$ 1982; 202: 275-8.

18 Deshmukh-Phadke K. Nanda S, Lee K. Macrophage factor that induces neutral protease secretion in normal rabbit chondrocytes. Eur J Biochem 1980; 104: 175-80. 